\title{
ARMADILHA PET COM PANO PRETO ENVOLVIDO EM FILME ADESIVO + ATRAENTE SINTÉTICO CAPTURA O MOSQUITO Aedes aegypti
}

\author{
Leila Eid Imad da Silva ${ }^{1}$ \\ Adriano Rodrigues de Paula ${ }^{2}$ \\ Anderson Ribeiro ${ }^{3}$ \\ Richard lan Samuels ${ }^{4}$
}

Resumo: O objetivo deste estudo foi avaliar a eficiência de uma "armadilha PET adesiva" com pano preto envolvido em filme adesivo associado a um atraente sintético para prender fêmeas de Aedes aegypti. Os tratamentos controles foram realizados com armadilha PET com: pano preto envolvido no filme adesivo sem o atraente, filme adesivo + atraente, e somente o filme adesivo. Os tratamentos foram realizados em quatro salas simulando cômodos residenciais. Cinqüenta fêmeas foram utilizadas em cada tratamento. Três repetições foram realizadas. Os mosquitos foram liberados em salas, expostos a uma armadilha de cada tratamento e as salas foram fechadas e lacradas. O experimento foi avaliado $24 \mathrm{~h}$ e $48 \mathrm{~h}$ depois de montado. No total, 31,3\% dos mosquitos foram capturados quando expostos por $24 \mathrm{~h}$ à "armadilha PET adesiva". Com o aumento do tempo de exposição (48h) a porcentagem de captura dobrou (66,6\%). Nos tratamentos controles a menor taxa de captura de mosquitos (3,33\%) ocorreu quando se utilizou a armadilha PET somente com filme adesivo por 24h. A armadilha PET adesiva poderia no futuro ser utilizada em residências. Palavras-chave: Vetor da dengue; Armadilha adesiva, Semicampo.

\footnotetext{
1 Universidade Estadual do Norte Fluminense - Centro de Ciências e Tecnologias Agropecuárias - Laboratório de Entomologia e Fitopatologia, Av. Alberto Lamego, 2000, Campos dos Goytacazes-RJ, Brasil. E-mail: imad.saudecoletiva@gmail.com.

2 Universidade Estadual do Norte Fluminense - Centro de Ciências e Tecnologias Agropecuárias - Laboratório de Entomologia e Fitopatologia, Av. Alberto Lamego, 2000, Campos dos Goytacazes-RJ, Brasil. E-mail: biodepaula@yahoo.com.br.

3 Universidade Estadual do Norte Fluminense - Centro de Ciências e Tecnologias Agropecuárias - Laboratório de Entomologia e Fitopatologia, Av. Alberto Lamego, 2000, Campos dos Goytacazes-RJ, Brasil. E-mail: anderson.ribeirorj@yahoo.com.br.

4 Universidade Estadual do Norte Fluminense - Centro de Ciências e Tecnologias Agropecuárias - Laboratório de Entomologia e Fitopatologia, Av. Alberto Lamego, 2000, Campos dos Goytacazes-RJ, Brasil. E-mail: richard@uenf.br
} 